\section{Diversão em movimento: um projeto lúdico para crianças hospitalizadas no Serviço de Oncologia Pediátrica do Instituto Materno Infantil Prof. Fernando Figueira, IMIP}

\section{Ludotherapy for hospitalized children: a ludotherapy program for hospitalized children in the Pediatrics Oncology Unit of the Instituto Materno Infantil Prof. Fernando Figueira, IMIP}

Arli Melo Pedrosa1 Hélio Monteiro2 Kelly Lins 3 Francisco Pedrosa4 Carolina Melo5

1-5 Unidade de Oncologia Pediátrica Hospital do Instituto Materno Infantil prof. Fernando Figueira, IMIP. Rua dos Coelhos, 300. Recife, PE, Brasil. CEP: 50.070-550. E-mail: arli.pedrosa@ cehope.com.br

\begin{abstract}
This paper describes a ludotherapy program implemented in the pediatrics oncology ward of the Instituto Materno Infantil Prof. Fernando Figueira (IMIP) with 60 malignant neoplasia patients from January 2004 to January 2005. It describes the phases of the project, demonstrates results obtained, relating learning development phases and ludic tools used as a resource to mitigate hospitalization hardships through the most requested items. Jean Piaget and Bruno Bettelheim concepts were used in this assessment.
\end{abstract}

Key words Child and juvenile cancer, Hospitalized children, Ludotherapy

\section{Resumo}

O presente trabalho descreve as atividades lúdicas desenvolvidas na enfermaria de oncologia pediátrica do Instituto Materno Infantil Prof. Fernando Figueira (IMIP), com 60 pacientes portadores de neoplasias malignas, no período de janeiro de 2004 a janeiro de 2005. Descreve também as etapas do Projeto e apresenta os resultados obtidos, correlacionando as etapas do desenvolvimento da aprendizagem com os instrumentos lúdicos utilizados como recurso minimizador do processo de hospitalização, através dos itens mais solicitados, considerando, para essa análise, as idéias de Jean Piaget e Bruno Bettelheim.

Palavras-chave Câncer infanto-juvenil, Criança hospitalizada, Ludoterapia 


\section{Introdução}

O avanço científico na área de oncologia infantojuvenil vem aumentando os índices de cura e sobrevida de crianças acometidas por câncer, principalmente quando ocorre o diagnóstico precoce.

$O$ processo de tratamento do câncer infantil demanda um tempo considerável de hospitalização, no qual a criança é submetida a procedimentos invasivos e dolorosos, como é o caso da quimioterapia e seus efeitos colaterais.

Essa idéia é contextualizada por Rossit e Kovacs (1998: 59) ${ }^{1}$ quando afirmam que a hospitalização de crianças com câncer

[...] é uma vivência traumática, onde parecem

esquecer que a criança é criança, que necessita de espaço

físico, atividades e atenção apropriadas à sua faixa etária.

A hospitalização pode comprometer o desenvolvimento normal da criança com câncer, devido à quebra de sua rotina anterior e ao processo de adaptação à nova realidade (rotina hospitalar: exames, procedimentos dolorosos, horários, visitas, etc.), podendo acarretar alterações físicas e mentais.

Observa-se que, além das dificuldades que a própria doença traz, as condições de hospitalização podem afetar a totalidade da criança, de forma que os seus desenvolvimentos físico, emocional e intelectual fiquem comprometidos.

Cada criança internada deixou para trás o mundo das coisas comuns: os pais, a casa, os irmãos, a escola, os amigos, os bichos de estimação, os brinquedos. Os acompanhantes, em sua maioria as mães, estão presentes, mas há angústia em seus semblantes. Por tudo isso, nossas crianças são muito tristes, e a internação é um momento no qual, além da doença, a criança vivencia 1 :

- A separação das pessoas com as quais possui vínculo afetivo.

- A mudança de espaço físico - do lar para o hospital.

- A diminuição da experimentação e da exploração.

- Procedimentos terapêuticos invasivos, dolorosos, causando medo e emoções de sofrimento ou morte.

Partindo dessas alterações, ocorridas repentinamente na vida da criança, nota-se a importância de projetos que incluam uma assistência adequada e que visem, através de ações lúdicas, minimizar os efeitos da hospitalização e prevenir sofrimentos mentais (psicológicos)

Dentre as possíveis estratégias utilizadas pela criança para enfrentar o processo da hospitalização, encontra-se o brincar e a leitura, sendo essas práticas próprias de seu momento de vida, nas quais ela descobre, experimenta, inventa, exercita e confere suas habilidades, além de terem estimuladas a criatividade, a iniciativa e a autoconfiança, ações sempre presentes nos projetos implementados pela equipe interdisciplinar da Unidade de Oncologia Pediátrica do Instituto Materno Onfantil Professor Fernando Figueira (IMIP) Centro de Hematologia e Oncologia Pediátrica (CEOPE), Recife, Pernambuco, Brasil.

Nessa perspectiva, caracteriza-se o Projeto Diversão em Movimento, ação implementada em setembro de 2003, como iniciativa de humanização hospitalar, que utiliza o lúdico como recurso terapêutico, objetivando oferecer materiais de entretenimento e educativos às crianças internadas na enfermaria oncológica pediátrica do IMIP. Esse projeto proporciona às mesmas o direito de brincar e a continuidade do seu desenvolvimento nas áreas física, afetiva, cognitiva, pessoal e social. Favorece também uma melhora na qualidade de vida dessas crianças, facilitando a prática da equipe multidisciplinar.

\section{O espaço físico}

O Serviço de Oncologia Pediátrica do IMIP foi fundado em maio de 1994, fruto de uma parceria estabelecida entre essa instituição hospitalar e o Centro de Hematologia e Oncologia Pediátrica . O Serviço atende a todos os pacientes com suspeita ou diagnóstico de neoplasia maligna, com idade entre 0 e 21 anos.

De maio de 1994 a setembro de 2005, o Serviço atendeu a 1374 casos novos de câncer, sendo o tipo mais freqüente as leucemias agudas, representando $43 \%$ do total dos pacientes (Figura 1).

Como pode ser observado no Figura 1, 78\% dos pacientes atendidos são procedentes de cidades do interior do Estado; $15 \%$, da capital; e 7\%, de outros Estados. Isso nos possibilita identificar um público com características interioranas visíveis e que vivencia o brincar e, conseqüentemente, a ludicidade, de maneira intensa.

Além do atendimento médico específico, os pacientes recebem o tratamento de suporte, que engloba os atendimentos psicossocial, terapêutico, odontológico e educativo, possibilitando registrar um percentual de cura que atinge $70 \%$, devido também ao suporte oferecido ao paciente e aos familiares na condução do tratamento. 


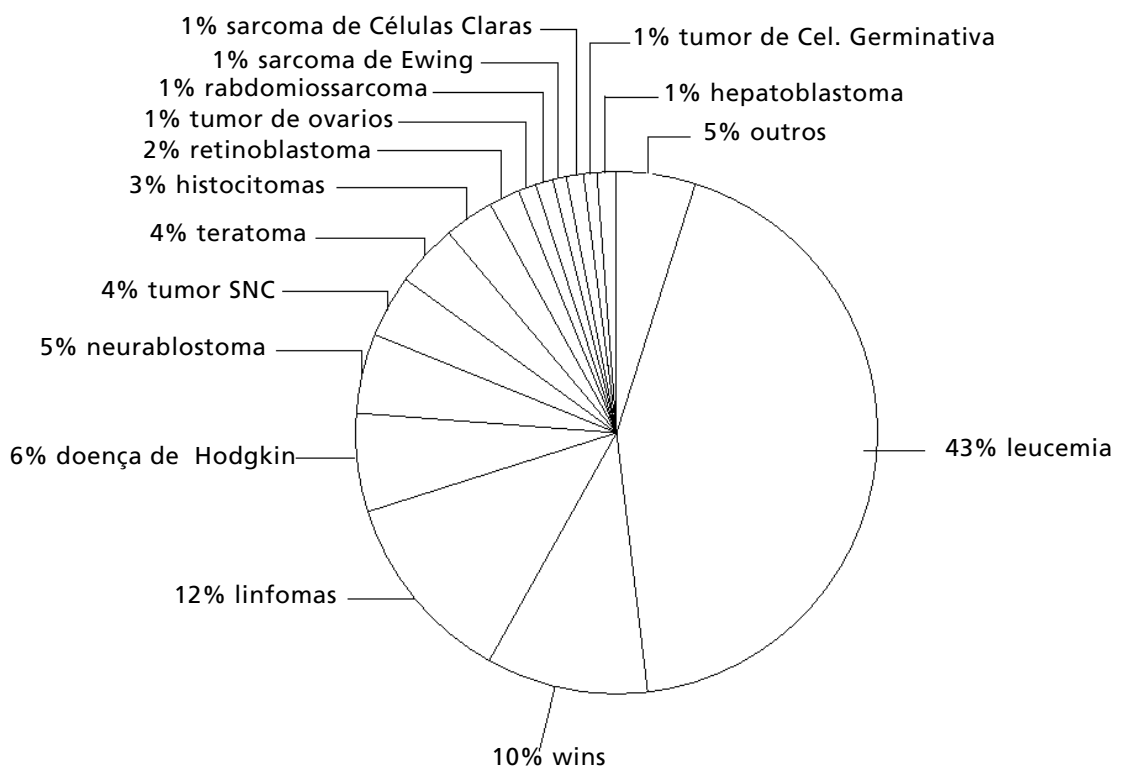

Procedência dos pacientes. Serviço de Pediátrica. Centro de Hematologia e Oncologia Pediátrica do Instituto Materno Infantil Prof. Fernando Figueira, IMIP. Recife, maio a setembro de 2005

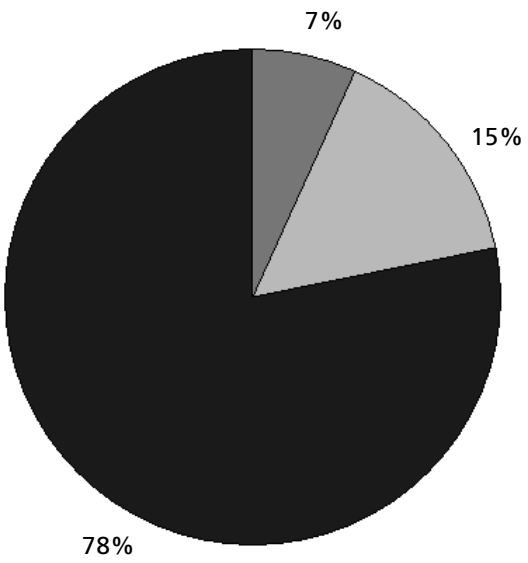

Recife

Interior

Outros Estados

Fonte: Instituto Materno Infantil Prof. Fernando Figueira, IMIP.

\section{Métodos}

Participaram desse Projeto crianças de ambos os sexos, na faixa etária citada anteriormente, internadas na enfermaria oncológica pediátrica do IMIP. Os profissionais que atuaram no Projeto foram uma psicóloga, um bibliotecário, dois médicos e uma terapeuta ocupacional, sendo esta última responsável pela intervenção no setor. Houve ainda a colaboração de voluntários para a execução do Projeto.
Os recursos lúdicos (livros, brinquedos, papéis, lápis de cor, hidrocor) foram disponibilizados em um carrinho de curativos, adaptado para percorrer as enfermarias, proporcionando diversão e descontração; daí o nome Diversão em Movimento (Figuras 2, 3 e 4). 


\section{Acervo}

A diversidade de recursos lúdicos disponibilizados, como pode ser analisada nas figuras, não impede que a criança vivencie momentos dolorosos, mas possibilita que ela libere sentimentos de raiva e hostilidade provocados pelo tratamento e por suas conseqüências. ${ }^{2}$ Dessa forma, colabora-se para que a criança possa ampliar seus conhecimentos sobre o seu corpo e os procedimentos terapêuticos a que será submetida.

Durante a semana, no horário das 13 horas, o carrinho itinerante percorria as enfermarias do Serviço de Oncologia Pediátrica do Imip, disponibilizando seus itens, e, às 17 horas, o material era recolhido. As atividades tinham começo, meio e fim no mesmo dia, com o propósito de educar e informar as crianças sobre a necessidade das regras na vida.

\section{Figura 2}

Recursos lúdicos: carrinho de curativos.

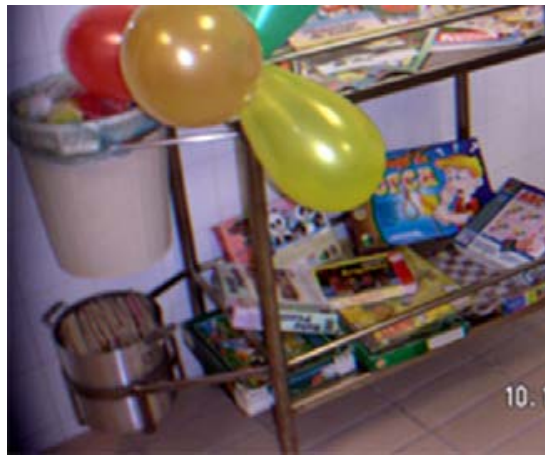

Fonte: Instituto Materno Infantil Prof. Fernando Figueira (IMIP).

\section{Figura 3}

Recursos lúdicos: livros e brinquedos.
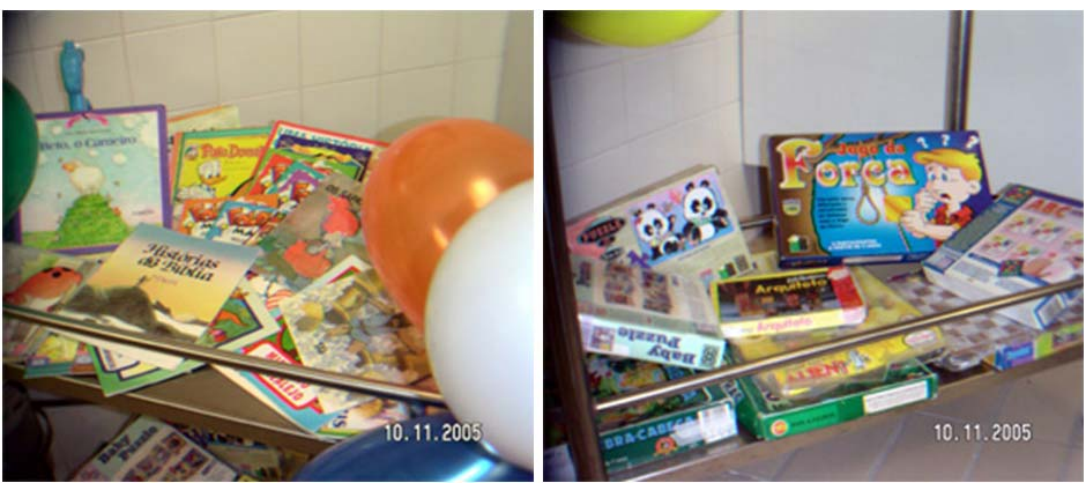

Fonte: Instituto Materno Infantil Prof. Fernando Figueira (IMIP).

Figura 4

Diversão e descontração.
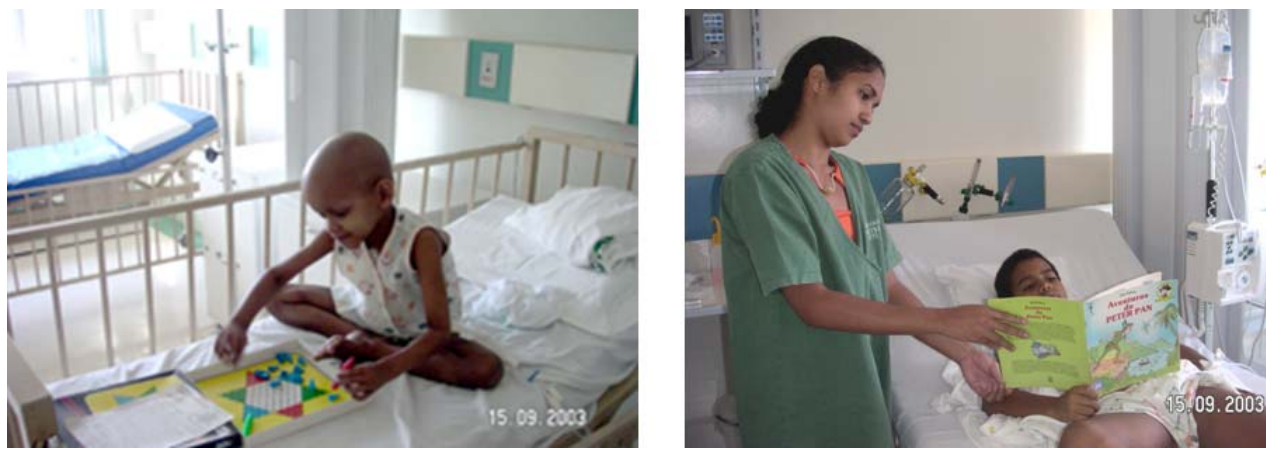

Fonte: Instituto Materno Infantil Prof. Fernando Figueira (IMIP). 
Os livros e os brinquedos, adquiridos através de doações, foram selecionados, catalogados e disponibilizados para um controle e melhor aproveitamento do material a ser utilizado pelos pacientes e acompanhantes. Para facilitar a indicação do material, eles foram separados por faixa etária. Vale salientar que não houve interferência dos profissionais na escolha dos livros e dos brinquedos por parte dos pacientes e acompanhantes.

Os materiais disponibilizados no carrinho eram reciclados a cada quinze dias. Os brinquedos passavam por um processo de desinfecção, conforme orientação da Comissão Interna de Controle de Infecção (CCIH).

\section{Resultados}

O Projeto possibilitou a aproximação entre todas as pessoas envolvidas no processo de hospitalização, contribuindo para a humanização e o enriquecimento do ambiente hospitalar.

A análise dos dados ocorreu através do método de observação e da aplicação de questionários, que permitiram avaliar os pacientes e seus acompanhantes.

De modo geral, ocorreu uma grande euforia e alegria com a implantação de algo novo na rotina das crianças hospitalizadas. Pelas reações, observou-se o benefício proporcionado pela oportunidade de acesso aos recursos lúdicos, estando esses itens sempre presentes no dia-a-dia da enfermaria, evidenciando resultados bastante positivos.

A diversidade existente entre as crianças hospitalizadas, no que diz respeito à idade, às condições físicas e ao interesse, fez com que tivéssemos uma grande variedade de materiais lúdicos e educativos no Projeto.

O estímulo à iniciativa da escolha do material torna a criança mais independente, além de estimular a comunicação e o interesse pelo Projeto. Com base nessas observações, caracterizou-se a escolha de acordo com as etapas do desenvolvimento propostas por Piaget, ${ }^{3}$ discriminados a seguir:

\section{Período Sensório-motor}

As crianças de zero a dois anos necessitam do auxílio dos acompanhantes no momento de escolha, quando geralmente optam por jogos de encaixes, bichinhos emborrachados e livros infantis. Essa fase é propícia para os estímulos visual e sonoro, para a qual são importantes: brinquedos coloridos, que se movimentam, sonoros e de pano. Livrinhos com figuras coloridas e de montagem chamam a atenção e divertem as crianças e seus acompanhantes.

O importante é valorizar os campos visual e auditivo, aspectos importantes para a aprendizagem, e não esquecer que, nessa fase, a criança recebe informações através dos sentidos, levando tudo à boca, aumentado o cuidado da equipe e dos acompanhantes, tendo em vista o momento de vida.

Nesse período, as crianças gostam de manipular objetos - retirar, colocar, atirar, empilhar, entre outras atividades -, tornando-se importante oferecer muitos materiais para isso.

\section{Período das Operações Concretas (pré- operacional, pré-conceitual, intuitivo e subestágios das operações concretas)}

Nas crianças entre 2 e 12 anos de idade, ficou evidente o entusiasmo quando o Projeto Diversão em Movimento começou a percorrer as enfermarias em que estão internadas. Nessa fase, as crianças começam a relacionar tudo o que acontece ao redor com seus sentimentos e ações. A linguagem verbal se desenvolve bastante, a criança quer saber o nome de tudo e define as coisas pela sua função. Começa o interesse pela leitura, e há o gosto de reconhecer figuras. $\mathrm{O}$ faz-de-conta se faz presente, reproduzindo o seu cotidiano.

Isso se confirma quando as crianças optam por telefones, panelinhas, objetos domésticos, objetos de uso dos médicos e das enfermeiras, bonecas, quebracabeças simples, carros, caminhões, balde e pazinha, fantoches, bichinhos de plástico, etc.

No período intuitivo, a criança começa a questionar. Suas razões são baseadas em seus desejos ou temores. Está mais hábil e gosta de montar e desmontar, assim como de desenhar. A solicitação de desenhos para pintura foi uma constante. Alguns dos brinquedos mais solicitados foram: blocos de construção, jogos de dominó, bingo, resta um, carrinho de boneca e jogo de damas. Também gostavam que lhes contassem histórias e eram capazes de prever situações. Para esse grupo, as leituras mais solicitadas foram os contos de fadas, talvez por trazerem elementos simbólicos contidos em seus dias de internação. Essa idéia confirma-se quando Coelho (2000: 15 e 35) 15 afirma que:

A literatura infantil e, principalmente, os contos de fadas podem ser decisivos para a formação da criança em relação a si mesma e ao mundo à sua volta. O maniqueísmo que divide as personagens em boas e más, belas e feias, poderosas ou fracas, etc., facilita, à criança, a compreensão de certos valores básicos da conduta humana ou do convívio social. 
Figura 5

Aprovação do público participante.

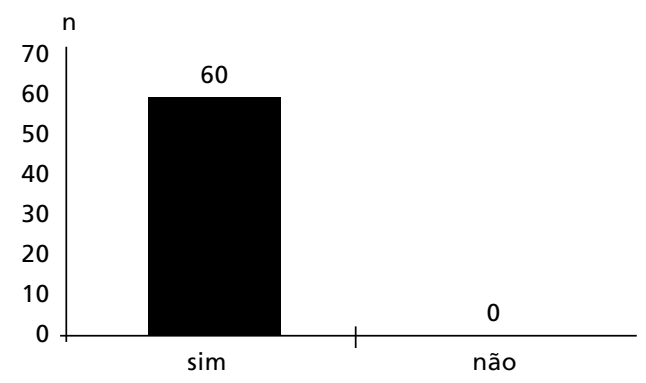

Fonte: Questionários da pesquisa

$\mathrm{n}$ = número de questionários

Essa afirmação nos faz entender que, ao lermos uma boa narrativa, de alguma forma, sabemos que, naquele momento, estamos recebendo informações de outra ordem e que, através das histórias, somos capazes de viver muito além da nossa realidade. Enquanto acompanhamos os encontros e desencontros dos personagens, temos a oportunidade de refletir sobre os nossos próprios problemas, solidificando, assim, a idéia de que crianças hospitalizadas precisam se abstrair do momento em que vivem.

\section{Período das Operações Formais}

Os pacientes de 12 anos em diante demonstraram inicialmente mais timidez, preferiam assistir à televisão, porém, através do estímulo à comunicação e à ação, também fizeram escolhas dentre os materiais disponíveis, tais como: jogos de quebra-cabeça, dominó, baralho, pega-varetas e livros.

$\mathrm{O}$ interesse pelos contos de fadas e pelas sagas ainda é evidente nessa fase, mas também começa a surgir o anseio pelas aventuras. Bamberger ${ }^{5}$ diz que o gosto pela leitura, para o público dessa faixa etária, pode ser despertado principalmente através do enredo, dos acontecimentos, do sensacionalismo. "O interesse geral é em torno de livros de aventuras, romances sensacionais, livros de viagens, histórias ordinárias e de sentimentalismo barato."

O Projeto fez com que os acompanhantes participassem das atividades escolhidas por seus filhos/parentes internados ou, quando não dessa forma, desenvolvessem atividades próprias, através de materiais destinados a eles, como, por exemplo: revistas e palavras-cruzadas. Esta última é mais freqüente aos acompanhantes dos pacientes que se encontram na Unidade de Terapia Intensiva.

\section{Avaliação dos Resultados}

Refletindo sobre os sessenta questionários aplicados em três períodos distintos - o primeiro, seis meses após a implantação do Projeto (janeiro de 2004); outro, após um ano (julho de 2004); e o último, um ano e meio depois (janeiro de 2005) -, obedecendo ao mesmo intervalo de tempo para os pacientes internados e seus acompanhantes, obtivemos os seguintes resultados:

Como pode ser observado na Figura 5, o Projeto teve aprovação total do público participante.

De acordo com o levantamento realizado, os brinquedos, jogos e livros mais solicitados pelas crianças foram:

Brinquedos: palhaço para montagem, carrinhos, bonecas, casinhas e chocalhos.

Jogos: dama, dominó, quebra-cabeça, jogo da memória, jogo de encaixe (blocos).

Livros: A Bela e a Fera, Cinderela, Branca de Neve, Os Três Porquinhos, Chapeuzinho Vermelho, Bambi, O Patinho Feio, Pinóquio, O Pequeno Polegar, A Flor da Raiz Vermelha, Piadas do Louro José, Tom e Jerry e Histórias Infantis. Este último é uma coletânea de histórias produzidas pelos próprios pacientes.

Diante dos itens, pode-se dizer que o jogo, como recurso integrador, é fundamental para despertar o interesse da criança. À medida que joga, ela vai se conhecendo melhor, construindo interiormente o seu mundo e desenvolvendo habilidades operatórias. Ela vai reconhecendo suas possibilidades e desenvolvendo, cada vez mais, a autoconfiança.

Piaget, citado por Zacharias, 6 descreve quatro estruturas básicas de jogos infantis: jogo de exercício, jogo simbólico/dramático, jogo de construção e jogo de regras. A importância do jogo de regras, segundo o autor, se dá quando a criança aprende a lidar com a delimitação - no espaço, no tempo, no tipo de atividade válida -, com o que pode ou não pode fazer, garantindo, assim, uma certa regularidade que organiza a ação, tornando-a orgânica.

Para as crianças hospitalizadas, esse reconhecimento da delimitação do espaço e do tempo e o respeito às regras, seja através do jogo, seja dos livros infantis, torna-se imprescindível, tendo em vista as restrições do tratamento. Observa-se que o encanto pelos livros é intenso, principalmente pelos contos de fadas.

Para Bettelheim, ${ }^{7}$ o conto de fadas ajuda a nos entendermos melhor, transmitindo à criança uma compreensão intuitiva e subconsciente de sua própria natureza e do que o futuro pode lhe reservar se ela desenvolver seus potenciais positivos. $\mathrm{O}$ autor 
afirma ainda que a criança, com os contos de fadas, percebe que o ser humano, neste nosso mundo, tem de aceitar desafios difíceis, mas, por outro lado, pode também vivenciar aventuras maravilhosas.

Essas informações clarificam as escolhas dos livros no Projeto; entre os contos de fadas, destacamos, pela interpretação possível, os livros: A Bela e a Fera, que propicia a integração entre o fácil e o difícil, uma situação bela (a infância) e outra feroz (o tratamento), porém tendo um final feliz. Os Três Porquinhos, que representa a passagem pelas fases da vida com um final feliz (casa de palha - infância; casa de madeira - adolescência; e casa de tijolo - fase adulta), apesar dos problemas (lobo).

Mesmo com acervo diversificado, apresentando outros itens (livro de fábulas, coleções), as crianças e seus acompanhantes fizeram sempre solicitações expressas verbalmente. Destacaram-se, entre os pedidos, as palavras-cruzadas, os gibis, as revistas e os desenhos para colorir.

Entre sugestões, observações e críticas acerca do Projeto, destacaram-se os seguintes comentários dos acompanhantes e pacientes:

Contribui para o grupo, que precisa de um tempo mais lúdico.

\section{Acompanhante A}

No início, ela era muito agressiva e, com o passar dos dias, foi se adaptando ao Projeto. Atualmente, já faz suas escolhas, ou seja, o Projeto está contribuindo ao tratamento e à sua adaptação.

\section{Acompanhante B}

A idéia do carrinho é muito boa porque, quando estamos internados, ficamos muito tempo sem diversão.

Paciente A

Essa necessidade de diversão é confirmada por Meirelles e Oliveira, ${ }^{8}$ quando diz em que, ao brincar, a criança fantasia, supõe, imita e cria enredos próprios que a ajudam a compreender o mundo. $\mathrm{O}$ encontro entre o mundo externo (compartilhado) e o mundo interno (das idéias, dos anseios e da imaginação) é freqüente, e, conseqüentemente, quanto mais rica em recursos internos a criança for, maior chance de sucesso na solução desses encontros ela terá. Isso nos respalda ainda mais para a continuidade do Projeto.

Muito bom para distrair as crianças e divertir.

Acompanhante $\mathrm{C}$

Acho que o carrinho contribuiu para animar meu filho.

\section{Acompanhante D}

Acho que deveria ter uma sala de brinquedos nos andares, para que as crianças passassem uma boa parte do tempo brincando. Pois as crianças, quando estão inter- nadas, passam boa parte do tempo dentro do quarto e

tristes.

Acompanhante D

O Projeto contribuiu para fazer com que as crianças

esqueçam, por um momento, do tratamento.

Acompanhante E

O Projeto abordou a experiência do brincar numa dimensão importante do desenvolvimento infantil afetada pela hospitalização, contribuindo para a diminuição da angústia da criança e reaproximandoa de suas atividades lúdicas e educativas.

\section{Considerações finais}

Os resultados obtidos sugerem que o Projeto atingiu o objetivo, na medida em que tornou o ambiente hospitalar mais agradável à criança e permitiu, de forma favorável, a continuidade do desenvolvimento humano, através do prazer de ler e de brincar.

Apesar de a criança se encontrar em situação desagradável (distante da família e adoecida), ela pode vivenciar esse momento de forma mais agradável; é o que sugere o resultado do Projeto Diversão em Movimento.

Acredita-se que ainda há muito por se fazer nessa área da hospitalização infantil, como, por exemplo, trabalhar as questões da socialização, da integração e da própria inclusão. Procurou-se desmistificar o pavor da rotina hospitalar, transformando-a em brincadeiras lúdicas, que podem ajudar a criança com câncer a aliviar e resolver conflitos e até lidar com eles, assim como conversar com naturalidade com crianças e pais, reduzindo o medo e a angústia originados pela doença e pelos períodos de internamento.

Que o Diversão em Movimento leve as crianças hospitalizadas a caminhos de alegrias, encantamento e que possa estabelecer um canal de aprendizagem. 


\section{Referências}

1 Rossit RAS, Kovacs, ACTB. Intervenção essencial de terapia ocupacional em enfermaria pediátrica. Cad Terap Ocup UFSCar. 1998; 7: 58-67.

2 Melo LL, Valle ERM. O brinquedo na assistência de enfermagem à criança com câncer [tese doutorado]. Ribeirão Preto: Escola de Enfermagem de Ribeirão Preto, Universidade de São Paulo; 2003

3 Terra MR. O desenvolvimento humano na teoria de Piaget. Disponível em URL: http://www.unicamp.br/iel/site/ alunos/publicacoes/textos/d00005.htm [2005 jul 15].

4 Coelho NN. A literatura infantil: abertura para a formação de uma nova mentalidade. In: Literatura infantil: teoria, análise, didática. São Paulo: Moderna; 2000. Pt.1: p.14-45.

Recebido em 22 de novembro de 2006

Versão final apresentada em 30 de outubro de 2006

Aprovado em 15 de dezembro de 2006
5 Bamberger R. Como incentivar o hábito de leitura. 4 ed. São Paulo: Ática; 1988.

6 Zacharias VLCF. O jogo simbólico. Disponível em URL: http:www.centrorefeducacional.com.br/ojogosim.html. [2004 out 17].

7 Bettelheim B. Sobre a narrativa dos contos de fadas. In: A psicanálise dos contos de fadas. 16. ed. Rio de Janeiro: Paz e Terra; 2002. p. 185-91.

8 Meirelles S, Oliveira AL. Porque as histórias são importantes para a saúde das crianças. [São Paulo]:Fundação Abrinq; [2002]. 